\title{
Rural Nursing Students' Knowledge of HIV/AIDS, and Beliefs and their Attitude towards People Living with HIV/AIDS
}

\author{
Flore nce Ngozi Ugoji ${ }^{1, *}$, Roland Chukwudi Agokei \\ ${ }^{1}$ Department of Guidance and Counselling, Delta State University. P.M.B. 1, Abraka \\ ${ }^{2}$ Department of Guidance and Counselling, University of Ibadan
}

\begin{abstract}
One of the most complex and complicated health problems confronting the world today is HIV/AIDS. The pandemic of HIV/AIDS has been worldwide classified as the most deadly sexually transmitted disease ever to confront humanity. As no cure is yet found, the need to curb the problem is paramount for the continuity of the human race. The acceptance and care for people living with HIV/AIDS is one issue often undermined. Th is study investigated the knowledge, beliefs of rural nursing students' and attitude towards people living with HIV/AIDS. The descriptive survey design was emp loyed for this study. A sample of 150 nursing students were randomly selected for the study. A self developed scale was used for data collection from the participants. Data was analyzed using Pearson Product Moment Corre lation and Multiple regression statistics. The result indicated that there was significant relationship between the participants knowledge of HIV/AIDS, be liefs and attitude towards people living with HIV/AIDS. The two independent variables accounted for $32.1 \%$ variance of the attitude to people liv ing with HIV/AIDS. Based on these findings, it was suggested as a matter of urgency that adequate training be provided for nurses with regards to HIV/AIDS causes, mode of in fection, spread and management.
\end{abstract}

Keywords Knowledge, Beliefs, Attitude, Nursing Students, People, HIV/AIDS

\section{Introduction}

It is no gainsaying that the reports concerning the rapid spread of AIDS all over the world have increased the level of anxiety. Despite researches, propaganda and campaign on the Human Immuno-Deficiency Virus (HIV) and Acquired Immune Deficiency Syndrome (AIDS), there is still increase in this most dreaded infection[1]. Reports from various quarters suggest that the rate of HIV infection is on the increase in an alarming rate. Unfortunately for the past two decades when the epidemic was noticed in Nigeria, the National Policy on AIDS is yet to be promulgated[3]. Current statistics show that over forty million people are living with the virus and about two-third of this population is from sub-Saharan Africa.

To date, HIV prevention efforts in most countries have focused primarily on encouraging people, including those not at risk, to engage in safe sex practices. This means that people who know they are HIV positive have been largely ignored regarding prevention efforts in the Sub-Saharan HIV epidemic. Although some African countries have made some

* Corresponding author:

ngougoji@yahoo.com (Florence Ngozi Ugoji)

Published online at http://journal.sapub.org/ijpbs

Copyright (C) 2012 Scientific \& Academic Publishing. All Rights Reserved significant strides over the past few years to reduce thespread of HIV infection, the rate of HIV infection in these countries continue to be unacceptably high. Increasingly it has been recognized that, in order to be successful, HIV prevention efforts also have to target people living with HIV/AIDS (PLWHA). Considering the predictions of continuing increase in the population of PLWHA in sub-Saharan African countries, a shift towards the implementation and scaling up of behavioural and social support interventions for PLWHA status is needed.

However, it is observed that since the dreaded disease was discovered and publicised, a lot of attitude have been formed about the disease and the people living with it. Many of these attitudes are negative and could not in any way ameliorate the physical and psychological sufferings of the PLWHA nor reduce their increasing numbers. There are beliefs that HIV is transmitted through ways such as shaking of hands, sharing of glass, using of public toilet together, using of public swimming pool together, and so on. Some people avoid sitting near an infected person. Also, people say they would reject their infected friends and any infected student should not be allowed to enter any school. There are also misconceptions such as students believing that children would never be affected by the pandemic; belief that HIV positive people can be recognized by their appearance; belief that there is cure and vaccine for AIDS. 
Addressing the HIV prevention needs of PLWHA becomes even more of a priority in the light of studies illustrating that a significant minority of people living with HIV are still engaging in risky behavior[5];[9];[8],[11]; [12]; [17] Indeed, the 2002 national population-based survey in South Africa[20] showed risk behaviour to be a very common occurrence among PLWHA in South Africa who were aware of their HIV status. While the 2005 survey noted a significant improvement, nearly one third of PLW HA who were aware of their HIV status were still engaging in risky behaviour[19]. Interestingly, similar results to the 2005 survey were obtained in a study that was conducted among South African educators [21].

Many researchers have tried to establish the source of the prejudice against PLW HA, but the strategies have differed between studies. For instance, [4] applied a psychological model, called the integrated threat model. In this model, it is assumed that different types of threats produce fear that is seen as a major cause of prejudice towards people with AIDS. Other researchers have focused on accounts in which attitude towards a person with AIDS are based on perceived characteristics of the disease. Nevertheless, misplaced assumptions that one can contract HIV/AIDS through casual contact may result in a general fear of infected individuals and discriminatory behaviour towards them. A number of studies have tested this hypothesis and have found a correlation between false beliefs about the danger of infection through casual contact and prejudice toward PLWHA[6];[10]. When such attitude spread across caregivers such as rural nurses, it definitely could become a facilitator for the spread of the disease and increase in PLWHAs.

Rural nursing has to do with the practices of nursing and medical treatment in hospital and community settings outside of metropolitan and major provincial towns and cities. Generally, rural nurses practice in communities with a population of between 500 and 10,000 people who have limited access to medical and allied health services. These communities may be mining sites, tourist resorts, remote communities or satellite clinics on pastoral properties. Most times there is at least one medical practitioner living within the community. In many small rural hospitals, there is usually one registered nurse. The knowledge and attitude of health workers in relation to HIV is an important determinant of their willingness to care and the quality of the care they will render to HIV patient. Insufficient knowledge might cause negative attitude towards HIV-positive patients. The link between increased knowledge of the disease and improved attitude towards patients with HIV/AIDS has been documented[13]. Increased knowledge may cause resultant reduction in nurses' fear in caring for HIV infected patients[22]. Perception of risk in relation to care of HIV positive person potentially influences the willingness to provide care[16].

Rural nurses are integral members of the local commun ity and develop collaborative relationships with community members and other health professionals to provide a comprehensive health service. Because of the geographical is olation they often work independently, or as part of a small team and have to refer patients to other areas and disciplines for secondary and tertiary interventions. There is yet no cure for AIDS and education and prevention is critically important. With due cognizance of both the nature of the message that must be communicated, the nature of young people, in this case need appropriate intervention[21]. The study therefore investigated rural nursing students' knowledge of HIV/AIDS, be liefs and their attitude towards people living with HIV/AIDS in Africa context. Although effort has been made to keep every one abreast of the diverstating effect of the disease but some are still perpetually invloved in the act hence this study to create more knowledge of its effect.. Different attitudes have been formed about the disease and the people living with it. Many of these attitudes are negative and could not in any way ameliorate the physical and psychological sufferings of the PLWHA nor reduce their increasing numbers. These belief ranges from shaking of hands, sharing of glass, using of public toilet together, using of public swimming pool together, and so on. Also, there are misconceptions that students or children can never be effected by the pandemic; and believed that positive people can be recognized by their appearance; and this has made its incessant occurnace among youths due to their belief that there is cure and vaccine for AIDS. What is the propeling force working against people living with HIV/AIDS from having adequate care and support and the knowledge and attitude of health workers in relation to HIV as determinant of their willingness to care for is what this study stand to solve. This work adopted the integrated threat model by $\{4\}$. This work made use of quantitative research method grounded on questionnaire in eliciting data from respondents. The purpose is to investigate the attitudes, beliefs and knowledge of rural nurses about AIDS/HIV. The novelty of the research revealed that there was a significant positive realtionship that gave $\mathrm{r}(148)=$ $0.533, \mathrm{P}<.05$. which connotes that a broad knowledge of HIV/AIDS could enhance nursing students' attitude towards caring for people living with HIV/AIDS. Also, it was deduced from findings that Belief of HIV/AIDS among rural nursing student; which gave $\mathrm{r}(148)=0.261, \mathrm{P}<.05$. can enhance nursing students' attitude towards people living with HIV/A IDS.

\section{Research Hypothesis}

The following hypothesis were tested in this study

1.There is no significant relationship between knowledge of HIV/AIDS and attitude towards people living with HIV/AIDS among rural nursing student

2.There is no significant relationship between Belief of HIV/AIDS and attitude towards people living with HIV/AIDS among rural nurs ing student.

3.There is no significant joint and independent effect of knowledge belief and stigmatization on attitude towards 
people living with HIV/AIDS among nursing students.

\section{Methodology}

The methodology adopted for this study consists of the research design, population and sample, research instrument, procedure and data analysis.

\section{Research Design}

The research design employed to carry out this study is a descriptive survey method. This allows for the vivid description of events as they occur in the process of carrying out the study.

\section{Population and Sample}

Since the research focuses on the rural student nurses in Delta State, nurses were selected from the three Senatorial Districts into wh ich the State is politically divided. However, not just any hospital was considered; only hospitals that fall within the rural areas within these Districts were randomly selected for the study. For the purpose of this study and with the limit of time for the study, ten (10) hospitals were randomly selected from each Senatorial District; and five (5) nurses from each hospital. Th is amounts to fifty (50) nurses from each Senatorial District. Therefore, the research population consists of a total number of one hundred and fifty (150) nurses. Nursing profession being predominantly for female, only five males were among the subjects selected for the research.

\section{Research Instrument}

The data for this study was drawn from the questionnaire purposely designed to investigate the attitude, beliefs and knowledge of rural nurses about AIDS/HIV. The questionnaire was tagged "Rural Nurses' Attitudes, Beliefs and Knowledge on AIDS/HIV" (RNABK). The questionnaire contains two sections. The first section contains the socio-demographic characteristics (that is bio-data information) which includes sex, age, years of qualification, type of hospital, location of the hospital, religion and marital status of the respondents. The second section, which is sub-divided into three parts, investigates information as to the respondents' attitudes, beliefs and knowledge on the most dreaded disease, AIDS/HIV. The questionnaire is considered to be adequate to elic it the attitude, beliefs and knowledge of the rural nurses in Delta State about AIDS/HIV. Each of the one hundred and fifty respondents were required to give their responses to the questions on attitude, beliefs and knowledge on AIDS/HIV in the questionnaires. They are to tick an option from YES, NO and DO NOT KNOW as they fill appropriate to describe their attitudes, beliefs and knowledge. The scoring range from $1-0$, that is 1 for yes and 0 for the other responses.

\section{Procedure}

The researcher self-administered the questionnaires, this she did with the assistance of some undergraduate students she employed as questionnaire administers, who together with her administered the questionnaire. She moved round each of the selected hospitals together with the said administers to see the nurses sampled in the study. She was, however, confronted with certain difficulties because the nurses were not easily accessible as some of them complained of not having the time to respond to the questionnaire. Some actually declined to respond to the questionnaire until they were persuaded that the questionnaires were administered just for research and academic purposes.

\section{Data Analysis}

Our aim and objective in this study is to investigate the attitude, beliefs and knowledge of rural nurses in Delta State about AIDS/HIV. Therefore, the analysis was done to identify the attitude, beliefs and knowledge of rural nurses in Delta State about AIDS/HIV; and to quantify the nurses that have positive attitudes, beliefs and knowledge among the sampled nurses. Therefore, a percentile calculation of the respondents' positive and negative attitudes, beliefs and knowledge was carried out among rural nurses in Delta State.

\section{Results}

Table 1 shows that there was significant positive relationship between knowledge of HIV/AIDS and attitude towards people living with HIV/AIDS among and rural nursing student; $r(148)=0.533, \mathrm{P}<.05$. This implies that, knowledge of HIV/AIDS could enhance nursing students' attitude towards people living with HIV/AIDS. The hypothesis was therefore rejected. There was significant positive relationship between attitude towards people living with HIV/AIDS and Belief of HIV/AIDS among rural nursing student; $r(148)=0.261, \mathrm{P}<.05$. This implies that beliefs about HIV/AIDS can enhance nursing students' attitude towards people living with HIV/AIDS. The hypothesis was therefore rejected.

Table 2 shows that there was joint effect of the independent variables (knowledge, stig matization and belief about HIV/AIDS) on attitude towards people living with HIV/AIDS among nursing student $(\mathrm{R}=0.579, \mathrm{P}<.05)$. The combination of the independent variables accounted for $32.1 \%$ (adjusted $\mathrm{R}^{2}=0.321$ ) of the totalvariance in the nurses' attitude towards HIV/AIDS. The analysis of variance of the multiple regression data yielded an F-ratio value which was found to be significant of 0.05 Alpha level, F $(2,147)=$ $37.001, \mathrm{P}<0.05$. 
Table 1. Descriptive Statistics and Correlations among Variables

\begin{tabular}{ccccccc}
\hline & $\mathrm{X}$ & Mean & SD & & & \\
\hline & 150 & 3.29 & 11.63 & 1.00 & & \\
Attitude towards PLWHA & 150 & 28.7 & 4.22 & .533 & 1.00 & \\
Knowledge of HIV/AIDS & 150 & 7.31 & 7.19 & .261 & .318 & 1.00 \\
Belief of HIV/AIDS & 150 & \\
\hline
\end{tabular}

Table 2. Multiple Regression Analysis showing Joint Effect of the Independent Variables on Att it ude Towards HIV/AIDS

\begin{tabular}{cccccccc}
\hline & $\mathrm{R}$ & $\mathrm{R}^{2}$ & Adj R & F-Ratio & Beta & $\mathrm{t}$ & Sig \\
\hline $\begin{array}{c}\text { Combine effects } \\
\text { Knowledge of }\end{array}$ & .579 & .335 & .321 & 37.001 & & & \\
HIV/AIDS & & & & & .682 & 3.594 & .000 \\
Belief of & & & & .368 & -1.691 & .000 \\
HIV/AIDS & & & & & & & \\
\hline
\end{tabular}

From the result displayed in table 2 above each of the independent variables made significant individual contributions to the prediction of the criterion measure (attitudes to PLWHA) in varying weights, with the exception of beliefs. The result indicated that the following beta weights which represent the independent variables were observed; knowledge of HIV/AIDS $\beta=.682, \mathrm{t}=3.594, \mathrm{P}<$ 0.05 and Beliefs $\beta=-.368, \mathrm{t}=-1.691, \mathrm{P}<0.05$.

\section{Discussion}

The result from table 1 indicates that there was a significant positive relationship between knowledge of HIV/AIDS and nursing students' attitude towards PLWHA. The imp lication is that the knowledge of HIV/AIDS held by nursing students could have positive attitude towards PLWHAs. This finding corroborates the finding of $\{2\}$ in the study of HIV/AIDS related knowledge which he postulates that knowledge broadens an individuals life perspective, while $\{14\}$ went further to state that knowledge invites a level of awareness that minimizes distances and removes the enigma within the subject. This theory also asserted that for knowledge to be useful the message must be consistent with the required attitude of the person involved. In another study conducted by $\{8\}$ on concept of attitude by the HIV/AIDS workers he asserted that attitude can have a significant effect on behaviour.

The result from table 2 indicates that beliefs about HIV/AIDS are associated with nursing students' attitudes towards PLWHAs. This implies that the beliefs of people may enhance their attitude towards people living with HIV/AIDS. This was signified by positive correlation that exists between beliefs of people about HIV/AIDS and the corresponding attitude towards HIV/AIDS. Beliefs of people about HIV/AIDS may be affected by the variety of external variables which include age, gender, educational status, social class, religion, etc. this study corroborates $\{7\}$ which postulated that the beliefs of people are significant factors of attitude because this creates a person's awareness affection and the psychomotor domain about HIV/AIDS. This in turn determines whether an individual will have negative or positive attitude towards HIV/AIDS.

The result in table 2 states there was joint effect of the independent variables (knowledge, and belief about HIV/AIDS on attitude towards people living with HIV/AIDS among nursing student The combination of the independent variables accounted for $32.1 \%$ (adjusted $\mathrm{R}^{2}$ $=0.321$ ) of the total variance in the nurses' attitude towards HIV/AIDS. The remaining $67.9 \%$ could be attributed to factors not investigated in this study. The analysis of variance of the multiple regression data yielded an F-ratio value which was found to be significant of 0.05 A lpha level, $\mathrm{F}(2,147)=37.001, \mathrm{P} .<0.05$. Th is means that the knowledge individual holds about HIV, their belief about HIV/AIDS and their perception of stigmatization have a great impact on their attitude towards people living with HIV/AIDS. The study also reveals that knowledge and beliefs about HIV/AIDS had independent effect on attitude towards people living with HIV/AIDS.

\section{Conclusions}

The study investigated the impact of knowledge and beliefs of rural nursing students on attitude towards people living with HIV/AIDS. The global HIV/AIDS epidemic has its greatest impact on the Africa continent. In the last one decade, there has been drastic increase and disturbing high level of AIDS cases in Africa including Nigeria with the highest prevalence within the productive age of 15 and 30 years. If HIV/AIDS is allowed to continue to spread at the current rate, there is danger that quite a number of youth will not reach adulthood, many families will be destroyed and there will be many orphans for the communities to cater for. The positive attitude of special caregivers such as nurses towards PLWHAs to a large extent may act as the facilitator hope again and curtailing the wanton spread of HIV/AIDS. 


\section{Implication and Recommendations}

Based on the results of the findings, the following are therefore recommended.

1. Adequate training should be provided for the nurses with regards to HIV/AIDS causes, mode of infection, spread and management.

2. Efforts should be geared towards minimizing and managing stigmatization so as to better the attitude towards people living with HIV/AIDS or, HIV/AIDS patient should not be stigmatized in the society.

3. The need for Rural nursing students to develop counselling tendencies and competencies is essential for fruitful and unconditional relationships with PLWHAs.

4. Attempts should be made at challenging negative attitudes and beliefs about HIV/AIDS so as to encourage testing and safety of PLWHAs.

5. Workshops, seminars, conferences should be organized and used as vehicles to enlightening nursing students on the importance of appropriate knowledge, belief and attitude towards people living with HIV/AIDS eschewing stigmatization at all cost.

\section{REFERENCES}

[1] Achalu, E I (1993): Aids and other sexually transmitted Diseases. What everyone should know ( $2^{\text {nd }}$ Edition). Lagos: Simarch Nigeria Limited.

[2] Acquaviva and Culhane (1996) AIDS. Housing needs assessment: results from a consumer survey office of housing of community development, city of Philadelphia.

[3] Akintunde, P.G (2002): The influence of knowledge of HIV/AIDS on the sexual

[4] Berrenberg, J. L., Finlay, K. A., Stephan, W. G., \& Stephan, C. (2002). Prejudice toward people with cancer or AIDS: Applying the integrated threat model. Journal of Applied Behavioral Research. 7, 75-86.

[5] Crepaz, N. and G. Marks. 2002. "Towards an understanding of sexual risk behaviour in people living with HIV: A review of social, psychological and medical findings," AIDS 16: 135-149.

[6] Dias, S., Matos, M.G. \& Gonçalves, A. (2005). Preventing HIV transmission in adolescents: an analysis of the Portuguese data of Health Behaviour School Aged. Children. The European Journal of Public Health, 15 (3), 300 - 304.

[7] Fisher J.D, and Fisher W.A. (1996) Changing Aids risk behaviour. Effects of an intervention emphasizing aids risk reduction information, motivation and behavioural skills in a college student population Health Psychology 15 (2)114-123

[8] Gagne R.M. (1977) The conditions of learning. Holt Rinehart \& Winston New York.
[9] Hankins, C., Coutlee, F., Lapointe, N., Simard, P., Tran, T., Samson, J., Hum L. \& The Canadian Women's HIV Study Group. (1999). Prevalence of risk factors associated with human papillomavirus infection in women living with HIV. CMAJ 160, 185-191.

[10] Herek, G. M., J. P. Capitanio., \& K. F. Widaman. (2002). American Public Increasingly Blames People With AIDS and Misunderstands How HIV Is Transmitted. American Journal of Public Health, p. 92.

[11] Kalichman, S. C. (1999). Mandatory reporting of suspected child abuse ethics, law, and policy (2nd ed.). Washington, DC: American Psychological Association.

[12] Kalichman, S. C. (2000). HIV transmission and risk behaviors of men and women living with HIV-AIDS: Prevalence, predictors, and emerging clinical interventions. Clinical Psychology: Science and Practice, 7, 32-47.

[13] Kessler L, and Heeren TC. 1987Knowledge and attitude of AIDS health care provider before and after education programs. Public Health Reports; 102(3): 248-253.

[14] Lancaster J, Onega L, Forness D (1996) Community and Public Health Nursing, Fourth Edition. St. Louis, MO M osby

[15] Marks G, Richardson JL, Maldanado N. Self-disclosure of HIV infection to sexual partners. American Journal of Public Health 1991;81:1321-1323.

[16] Polgar, M. "Concern, Caution and Care: HIV Risk Perception Among Hospital Nurses," Sociological Inquiry, 70 (3), 253-279, 2000

[17] Robins, A.G. et al. (1994). Psychosocial factors associated with risky sexual behaviour among HIV-seropositive gay men. AIDS Education and Prevention, 6, 483-492.

[18] Shisana O \& Simbayi L (2002) Nelson Mandela/HSRC study of HIV/AIDS: South African national HIV prevalence, behavioural risks and mass media household survey 2002. Cape Town: HSRC Press

[19] Shisana O, Rehle T, Simbayi LC, Parker W, Zuma K, Bhana A, Connolly C, Jooste S, Pillay V, et al. (2005) South African national HIV prevalence, HIV incidence, behavior and communication survey, 2005. Cape Town: HSRC Press.

[20] Shisana, O. et al. (2005b). (Eds). The Health of our educators: A focus on HIV/AIDS in South African public schools. /Report on Factors Determining Educator Supply and Demand in South African Schools funded and prepared for the Education Labour Relations Council]. Cape Town: HSRC.

[21] Uwakwe, C. B. U. (1999). Aids Related knowledge, Opinion and Behaviour change among First Year Nigerian University Students. Nigerian Journal of Applied Psychology, 5 (1\&2), 8- 23.

[22] Valimaki, M., Suominen,T. \& Peate, I. (1998). Attitudes of professionals, students and the general public to HIV/AIDS and people with HIV/AIDS: A review of the research. Journal of Advanced Nursing, 27(4), 752-759. 